\title{
Identification of a role for serum aldo-keto reductase family 1 member B10 in early detection of hepatocellular carcinoma
}

\author{
CHAO HAN $^{1}$, LANZHU GAO ${ }^{1,2}$, HAN BAI $^{1}$ and XIAOGUANG DOU ${ }^{1}$ \\ ${ }^{1}$ Department of Infectious Diseases, Shengjing Hospital of China Medical University, Shenyang, \\ Liaoning 110022; ${ }^{2}$ Department of Infectious Diseases, Tongliao Infectious Diseases Hospital, \\ Tongliao, Inner Mongolia Autonomous Region 028000, P.R. China
}

Received March 6, 2018; Accepted September 6, 2018

DOI: $10.3892 / \mathrm{ol} .2018 .9547$

\begin{abstract}
Despite improved screening programs, the vast majority of patients with hepatocellular carcinoma (HCC) are diagnosed at an advanced stage. A lack of effective diagnosis methods for preclinical HCC has resulted in a low rate of early detection. Aldo-keto reductase family 1 member B10 (AKR1B10) is associated with several cancer types. However, to the best of our knowledge, the diagnostic value of AKR1B10 in early stage $\mathrm{HCC}$ is poorly understood. In the current study, the diagnostic performance of serum AKR1B10 in hepatitis $\mathrm{B}$ virus/hepatitis $\mathrm{C}$ virus (HBV/HCV)-related liver disorders was evaluated and the unique role of AKR1B10 in diagnosing HCC was assessed. Serum AKR1B10 was detected by sandwich ELISA in 84 patients with HBV/HCV-related HCC, 74 patients with liver cirrhosis, 29 patients with chronic hepatitis and 30 healthy controls. Serum AKR1B10 and $\alpha$-fetoprotein (AFP) levels were analyzed and compared. Elevated levels of serum AKR1B10 were identified in patients with HCC compared with patients with other liver disorders $(\mathrm{P}<0.05)$. Compared with advanced and terminal stage $\mathrm{HCC}$, a significant increase in AKR1B10 levels was primarily detected in early and intermediate stage HCC. The sensitivity (81.0\%) and specificity (60.9\%) for HCC diagnosis with AKR1B10 were high at a cutoff value of $1.51 \mathrm{ng} / \mathrm{ml}$. Conversely, a prominent increase in AFP was observed in advanced and terminal stage HCC. Furthermore, concurrent measurement of serum AKR1B10 and AFP significantly increased sensitivity and negative predictive value for HCC diagnosis. The results presented in the current study strongly indicate AKR1B10 has a unique role as a biomarker for early stage $\mathrm{HBV} / \mathrm{HCV}$-related HCC. Compared with AFP alone, a combination of serum
\end{abstract}

Correspondence to: Dr Xiaoguang Dou, Department of Infectious Diseases, Shengjing Hospital of China Medical University, 39 Huaxiang Road, Tiexi, Shenyang, Liaoning 110022, P.R. China E-mail: douxg@sj-hospital.org

Key words: aldo-keto reductase family 1 member B10, hepatocellular carcinoma, $\alpha$-fetoprotein, biomarker, early detection of cancer
AKR1B10 and AFP increased the diagnostic performance in patients with HCC. In summary, the current results identify a unique role of AKR1B10 in HCC diagnosis.

\section{Introduction}

Despite improved screening methods for the detection of potentially curable hepatocellular carcinoma (HCC), asymptomatic HCC is only sporadically diagnosed in patients (1). As a result, $\mathrm{HCC}$ is most commonly diagnosed in the advanced or terminal stage with the presence of intra- or extra-hepatic metastases (1). Therefore, HCC is one of the most lethal cancer types, with the third highest mortality rate of all cancer types worldwide, following lung cancer and gastric cancer (2). HCC has many risk factors, including hepatitis B virus (HBV) and hepatitis $\mathrm{C}$ virus ( $\mathrm{HCV}$ ), both of which cause acute and chronic infections that can lead to cirrhotic pathological processes, which are thought to be the underlying causes for $\operatorname{HCC}(1,3)$. Accumulating evidence suggests that HBV infection is associated with approximately $80 \%$ of HCC cases in China $(3,4)$, with this association continuing to increase in recent years (5). Surgical tumor resection is considered to be an effective treatment for early stage HCC, providing a good outcome in the majority of cases (6). Unfortunately, due to the suboptimal diagnostic methods available to detect individuals with a high risk of developing HCC, most patients are presented to clinicians with advanced stage $\mathrm{HCC}$, at which point a variety of treatment options are less effective, including surgical resection, liver transplantation and locoregional procedures including radiofrequency ablation (7).

In the last decade, several studies have identified that there are many serum biomarkers that have the potential to assist the early diagnosis of $\operatorname{HCC}(1,8,9)$. $\alpha$-fetoprotein (AFP) levels were detectable in the blood of many patients with advanced HCC (10,11). However, high AFP levels were unreliably detected in patients with early stage HCC. The diagnostic value of AFP is further complicated by the fact that it cannot provide significant discrimination between malignant and non-malignant liver disorders (1). Furthermore, an absence of AFP in certain patients with HCC was also identified (12). Therefore, exclusively using AFP as a diagnostic biomarker for the early detection of HCC is hindered by the aforementioned limitations. 
If properly validated, biomarkers circulating in the plasma or serum could serve as the criterion standard for non-invasive liver cancer diagnostics. Several other serum biomarkers have been identified and their potential as candidates for detection of early stage HCC has been thoroughly evaluated in recent years $(1,8,9)$. For example, AFP-L3 and des-gamma-carboxy prothrombin (DCP) have reportedly been useful in HCC screening (13). AFP-L3 is a glycoform of AFP, used for the early detection of HCC (14). AFP-L3 is exclusively derived from cancer cells $(9,15)$ and has a higher specificity for HCC compared with AFP (14). However, AFP-L3 is not typically detected when AFP levels are $<20 \mathrm{ng} / \mathrm{ml}(8)$ and it has a low sensitivity for early stage HCC diagnosis $(16,17)$. DCP is an abnormal prothrombin molecule that is increased in HCC, with a diagnostic sensitivity that may be greater compared with AFP (8). However, the detection of DCP alone exhibited a low sensitivity in the diagnosis of early stage HCC (18). It has previously been demonstrated that the sensitivity for diagnosing HCC could be substantially increased if both AFP and DCP levels were examined together (18-20). However, this approach appears to be less sensitive in detecting HCC when patients have AFP levels $<20 \mathrm{ng} / \mathrm{ml}$ (8). Therefore, there is an urgent need to identify novel and reliable biomarkers that can either replace or be used in combination with AFP for the detection of preclinical HCC.

As a key member of the aldo-keto reductase superfamily, aldo-keto reductase family 1 member B10 (AKR1B10) modulates cell growth and survival by regulating lipid synthesis $(21,22)$ and eliminating carbonyl compounds (23-28). These are key steps involved in the proliferation and development of tumors through the regulation of the retinoic acid signaling pathway $(29,30)$. AKR1B10 is overexpressed in several types of tumor tissue $(23)$, including HCC tissue $(31,32)$. AKR1B10 is mainly expressed in the cytoplasm and can be secreted through a lysosome-mediated non-classical pathway and regulated by lysosome exocytosis signaling (33). As an independent risk factor, AKR1B10 can exert its regulatory role in the initiation and development of HCC, suggesting it is involved in the molecular signaling pathways that lead to the development of HCC. However, to the best of our knowledge, this role of AKR1B10 is not well understood (34-36). The expression of AKR1B10 in patients with HCC is negatively associated with the degree of tumor differentiation; enhanced expression of AKR1B10 was identified in well-differentiated, low-grade HCC tissues and downregulated expression of AKR1B10 was identified in poorly differentiated, high-grade HCC tissues (32,37). Patients with low AKR1B10 expression appear to be associated with a poorer prognosis compared with those with positive expression following surgical resection of HCC tumors $(31,37,38)$. Although several studies have investigated serum AKR1B10 in patients with $\mathrm{HCC}$, to the best of our knowledge, the pattern of AKR1B10 expression in patients with early stage HCC is unclear.

In the current study, an attempt was made to characterize expression profiles of serum AKR1B10 and AFP in patients with HCC. Serum AKR1B10 levels were first measured in patients with different types of hepatic diseases using sandwich ELISA. Next, the diagnostic performance of AKR1B10 in patients with HCC was determined. Finally, AKR1B10 and AFP levels were assessed and evaluated to determine if these biomarkers provide optimal sensitivity and specificity for the detection of early stage HCC.

\section{Materials and methods}

Patients. The current study enrolled a total of 84 patients with HBV/HCV-related HCC (69 males and 15 females), 74 patients with $\mathrm{HBV} / \mathrm{HCV}$-associated liver cirrhosis (42 males and 32 females) and 29 patients with chronic hepatitis $\mathrm{B} / \mathrm{C}$ (14 males and 15 females). These patients were admitted to Shengjing Hospital of China Medical University (Shenyang, China) from September 2012 to October 2014. Eligible patients were confirmed to have a history of either hepatitis B surface antigen-/HBV DNA-positive or hepatitis $\mathrm{C}$ antibody-/HCV RNA-positive for at least 6 months. An additional 30 healthy subjects (14 males and 16 females) who underwent a routine health check at the same hospital during the same period of time were chosen as controls. The characteristics of all participants are summarized in Table I. The diagnostic criteria employed were based on the guidelines for the prevention and treatment for chronic HBV (2010 version) (39) and diagnosis, management and treatment of HCC (V2011) (1). The study protocols were reviewed and approved by the Intuitional Review Board and the Ethics Committee of Shengjing Hospital of China Medical University. Written informed consent was obtained from all participants prior to the start of the study. The identity of each participant, whose serum samples and medical records were obtained, was coded and later decoded after data analysis was completed.

Laboratory investigations. Blood samples collected from the patients and controls were tested by the Clinical Laboratory of Shengjing Hospital of China Medical University. An array of biochemical parameters and hepatic enzymes were specifically measured and analyzed, including alanine aminotransferase, aspartate aminotransferase, albumin, total bilirubin, prothrombin time international normalized ratio and AFP.

Sandwich ELISA. Serum AKR1B10 was detected by sandwich ELISA using the AKR1B10 ELISA kit (CSB-ELOO1540HU; Wuhan Institute of Biological Products Co., Ltd., Wuhan, Hubei, China). First, 96-well plates were coated with the purified antibody as the solid phase and the sample (100 $\mu \mathrm{l} /$ well) was added in triplicate. Plates were incubated at $37^{\circ} \mathrm{C}$ for $2 \mathrm{~h}$ and then incubated at $37^{\circ} \mathrm{C}$ for a further $1 \mathrm{~h}$ with $1: 100$ diluted biotin-labelled human AKR1B10 antibody (100 $\mu \mathrm{l} /$ well). After 3 washes ( 2 min each) with washing buffer ( $200 \mu \mathrm{l} /$ well), plates were incubated at $37^{\circ} \mathrm{C}$ for $1 \mathrm{~h}$ with $100 \mu \mathrm{l} /$ well of streptavidin-HRP conjugates, then washed 5 times ( 2 min each) with $200 \mu \mathrm{l} /$ well of washing buffer. 3,3',5,5'-Tetramethylbenzdine (90 $\mu \mathrm{l}$ ) was added to the wells and incubated at $37^{\circ} \mathrm{C}$ for $15 \mathrm{~min}$. Reactions were stopped with $50 \mu \mathrm{l} /$ well of stop solution. Using a plate reader, $\mathrm{A}_{450}$ values were read within $5 \mathrm{~min}$. Standard reagents were used for establishing a standard curve from which serum AKR1B10 concentration was calculated.

Statistical analysis. Analyses were performed using SPSS Statistics 17.0 (SPSS, Inc., Chicago, IL, USA). One-way analysis of variance (ANOVA), Fisher's exact test, Mann-Whitney 
Table I. Characteristics of all participants.

\begin{tabular}{|c|c|c|c|c|}
\hline Characteristics & $\mathrm{HCC}(\mathrm{n}=84)$ & Liver cirrhosis $(n=74)$ & Chronic hepatitis $(\mathrm{n}=29)$ & Healthy control $(n=30)$ \\
\hline Age, years, mean (range) & $57(33-78)$ & $55(31-75)$ & $36(23-57)$ & $32(28-40)$ \\
\hline \multicolumn{5}{|l|}{ Sex, $n$} \\
\hline Male & 69 & 42 & 14 & 14 \\
\hline Female & 15 & 32 & 15 & 16 \\
\hline \multicolumn{5}{|l|}{ Etiology, n } \\
\hline HBV infection & 71 & 41 & 17 & 0 \\
\hline HCV infection & 13 & 33 & 12 & 0 \\
\hline $\mathrm{ALT}, \mathrm{U} / 1$, mean $\pm \mathrm{SD}$ & $65.80 \pm 61.09$ & $75.80 \pm 101.80$ & $57.48 \pm 59.68$ & $26.23 \pm 6.48^{\mathrm{a}, \mathrm{b}}$ \\
\hline $\mathrm{AST}, \mathrm{U} / 1$, mean $\pm \mathrm{SD}$ & $98.70 \pm 86.37$ & $92.04 \pm 119.67$ & $49.21 \pm 39.07^{\mathrm{a}, \mathrm{b}}$ & $25.37 \pm 9.13^{\mathrm{a}, \mathrm{b}}$ \\
\hline Albumin, $g / 1$, mean \pm SD & $32.82 \pm 6.03$ & $33.52 \pm 6.79$ & $41.04 \pm 4.56^{\mathrm{a}, \mathrm{b}}$ & $39.81 \pm 3.75^{\mathrm{a}, \mathrm{b}}$ \\
\hline $\mathrm{TBil}, \mu \mathrm{mol} / 1$, mean $\pm \mathrm{SD}$ & $59.19 \pm 90.31$ & $47.23 \pm 74.16$ & $14.38 \pm 5.35^{\mathrm{a}, \mathrm{b}}$ & $11.50 \pm 3.96^{\mathrm{a}, \mathrm{b}}$ \\
\hline PT INR & $1.15 \pm 0.18$ & $1.16 \pm 0.27$ & $0.98 \pm 0.09^{\mathrm{a}, \mathrm{b}}$ & $0.93 \pm 0.09^{\mathrm{a}, \mathrm{b}}$ \\
\hline
\end{tabular}

${ }^{a} \mathrm{P}<0.05$ vs. patients with HCC. ${ }^{b} \mathrm{P}<0.05$ vs. patients with liver cirrhosis. HCC, hepatocellular carcinoma; HBV, hepatitis B virus; HCV, hepatitis $\mathrm{C}$ virus; ALT, alanine aminotransferase; AST, aspartate aminotransferase; TBil, total bilirubin; PT INR, prothrombin time international normalized ratio; SD, standard deviation.

$\mathrm{U}$ test and $\mathrm{Z}$ test were used for statistical inference, when appropriate. If a significant difference was identified by one-way ANOVA, a post hoc Fisher's least significant difference test was used to determine the difference within the groups. $\mathrm{P}<0.05$ was considered to indicate a statistically significant difference. Receiver operating characteristic (ROC) analyses compared the diagnostic performance of experimental parameters with a non-parametric method and the optimal cutoff value was screened and proposed. Data were presented as mean \pm standard deviation.

\section{Results}

Patient characteristics. A total of 187 patients and 30 healthy controls were enrolled and their demographic and biochemical characteristics are summarized in Table I. Among them, 84 patients $(44.9 \%)$ were confirmed to have HCC, 74 patients $(39.5 \%)$ were confirmed to have liver cirrhosis and 29 patients $(15.5 \%)$ were confirmed to have chronic hepatitis. There was a male predominance in HCC patients. Compared with the controls, there were significant differences in many demographic and biochemical characteristics among the groups. These differences were consistent with clinical practice after age and sex were factored into data analysis, and follow the general pathophysiological courses of development of liver diseases, including HCC, cirrhosis and chronic hepatitis.

Serum AKR1B10 and AFP levels in patients with various liver disorders. AKR1B10 levels in the serum samples obtained from the subjects in the different groups were compared using one-way ANOVA and the results are presented in Fig. 1A. The mean serum AKR1B10 level was significantly higher in patients with $\mathrm{HCC}(4.02 \pm 3.53 \mathrm{ng} / \mathrm{ml}, \mathrm{n}=84)$ compared with patients with liver cirrhosis $(2.61 \pm 2.0 \mathrm{ng} / \mathrm{ml}, \mathrm{n}=74)$, chronic hepatitis $(1.12 \pm 1.01 \mathrm{ng} / \mathrm{ml}, \mathrm{n}=29)$ or the controls $(0.76 \pm 0.74 \mathrm{ng} / \mathrm{ml}$, $\mathrm{n}=30 ; \mathrm{P}<0.05)$. Furthermore, a significant difference in serum
AKR1B10 expressions was evident between the patients with liver cirrhosis and those with chronic hepatitis $(\mathrm{P}<0.05)$, but not between patients with chronic hepatitis and the controls $(\mathrm{P}=0.584)$. This indicates that the production of AKR1B10 was enhanced when hepatocytes were undergoing cirrhosis. Additionally, a significant increase in AFP levels was identified in patients with $\mathrm{HCC}(566.82 \pm 1,196.90 \mathrm{ng} / \mathrm{ml}, \mathrm{n}=84)$, liver cirrhosis $(22.88 \pm 50.29 \mathrm{ng} / \mathrm{ml}, \mathrm{n}=74)$ and chronic hepatitis $(6.35 \pm 11.47 \mathrm{ng} / \mathrm{ml}, \mathrm{n}=29)$ when compared to the controls $(3.59 \pm 1.08 \mathrm{ng} / \mathrm{ml}, \mathrm{n}=30)$, as demonstrated in Fig. $1 \mathrm{~B}(\mathrm{P}<0.05)$.

Regardless of the etiology of the infection, no significant differences were identified in AKR1B10 expression when comparing patients with $\mathrm{HBV}$ and $\mathrm{HCV}$-related HCC $(\mathrm{P}=0.614)$, liver cirrhosis $(\mathrm{P}=0.384)$ or chronic hepatitis $(\mathrm{P}=0.452$; Table II), this suggests that release of AKR1B10 from the damaged hepatocytes is independent of the history of the viral infection. However, for patients with HBV infection, HCC had a significantly higher AKR1B10 expression compared with the liver cirrhosis and chronic hepatitis groups $(\mathrm{P}<0.05$; Table II). However no significant difference was revealed in AKR1B10 expression between the liver cirrhosis and chronic hepatitis groups $(\mathrm{P}=0.094)$. For patients with $\mathrm{HCV}$ infection, the HCC and liver cirrhosis groups exhibited a significant increase in AKR1B10 expression compared with the chronic hepatitis group $(\mathrm{P}<0.05)$. However no significant difference was identified in the expression levels between the $\mathrm{HCC}$ and liver cirrhosis groups $(\mathrm{P}=0.358)$.

Association of serum AKR1B10 and AFP levels in patients with different stages of $H C C$. The current study assessed the association of AKR1B10 and AFP levels in patients with HCC in relation to the stage of liver cancer, based on the Barcelona Clinic Liver Cancer (BCLC) staging classification (40). Patients with tumors that were in early, intermediate, advanced and terminal stages were selected for further subgroup analysis. As indicated in Fig. 2, significant differences were identified 
Table II. Association of AKR1B10 expression with viral etiology of liver disorders.

AKR1B10 (ng/ml)

\begin{tabular}{lccc}
\cline { 2 - 4 } Characteristics & HCC $(\mathrm{n}=84)$ & Liver cirrhosis $(\mathrm{n}=74)$ & Chronic hepatitis $(\mathrm{n}=29)$ \\
\hline HBV infection & $4.17 \pm 3.69(\mathrm{n}=71)$ & $2.52 \pm 2.21(\mathrm{n}=41)^{\mathrm{a}}$ & $1.04 \pm 1.04(\mathrm{n}=17)^{\mathrm{a}}$ \\
HCV infection & $3.27 \pm 2.56(\mathrm{n}=13)$ & $2.72 \pm 1.74(\mathrm{n}=33)$ & $1.24 \pm 1.00(\mathrm{n}=12)^{\mathrm{a}, \mathrm{b}}$ \\
P-value & 0.614 & 0.384 & 0.452
\end{tabular}

Data are presented as the mean \pm standard deviation. ${ }^{a} \mathrm{P}<0.05$ vs. patients with $\mathrm{HCC}$. ${ }^{\mathrm{b}} \mathrm{P}<0.05$ vs. patients with liver cirrhosis. AKR1B10, aldo-keto reductase family 1 member B10; HCC, hepatocellular carcinoma; HBV, hepatitis B virus; HCV, hepatitis C virus.
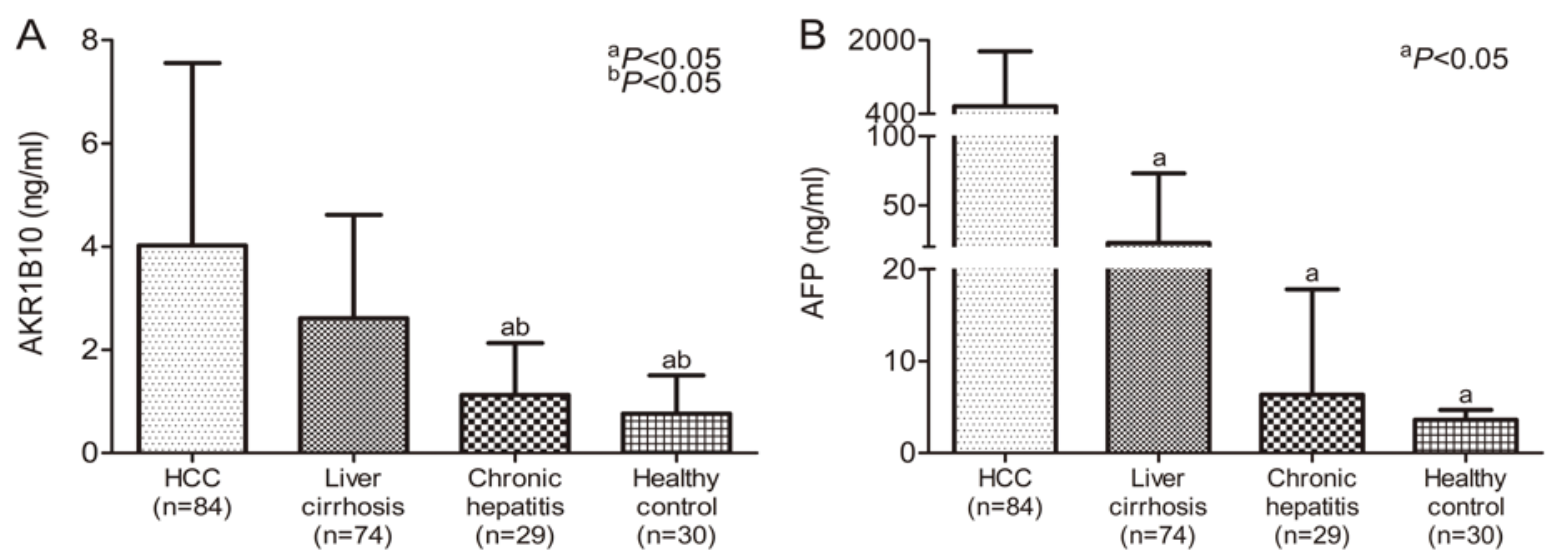

Figure 1. Serum AKR1B10 and AFP levels in patients with various liver disorders. (A) Mean serum AKR1B10 levels expressed in patients with HCC (n=84), cirrhosis $(n=74)$ and chronic hepatitis $(n=29)$ and controls $(n=30)$. A significant increase in AKR1B10 levels in patients with HCC and liver cirrhosis but not chronic hepatitis was identified compared with the controls. Overexpression of AKR1B10 was more prominent in the patients with $\mathrm{HCC}$. ${ }^{\mathrm{P}}<0.05$ vs. patients with HCC. ${ }^{b} \mathrm{P}<0.05$ vs. patients with liver cirrhosis. (B) A significant elevation of AFP levels was associated with HCC but not with liver cirrhosis or chronic hepatitis compared with the controls. ${ }^{\mathrm{a}} \mathrm{P}<0.05$ vs. patients with HCC. AKR1B10, aldo-keto reductase family 1 member B10; HCC, hepatocellular carcinoma; AFP, $\alpha$-fetoprotein.

between serum AKR1B10 and AFP levels at different stages. The highest AKR1B10 levels were identified in HCC patients in early and intermediate stages but they declined to a constant level in advanced and terminal stages (Fig. 2A). By contrast, the highest levels of AFP were detected in the advanced and terminal stages compared with the early and intermediate stages of HCC (Fig. 2B). The ratio of AKR1B10 to AFP was significantly higher in the early and intermediate stages compared with the advanced and terminal stages of HCC (Fig. 2C). The current results indicate that there are variations in the expression of AKR1B10 and AFP throughout the development of HCC. There is a clear increase in AKR1B10 levels but not AFP levels in early stage HCC. This suggests that AKR1B10 may be a primary factor involved in the development of HCC and could therefore be considered as a biomarker for the detection of early stage HCC. Conversely, serum AFP levels were only significantly higher when HCC was in the advanced or terminal stage.

Comparison of the sensitivity and specificity of serum AKRIB10 and AFP for the diagnosis of HCC. The sensitivity and specificity of serum AKR1B10 and AFP for diagnosing HCC were determined by generating an ROC curve (Fig. 3). When a cutoff value of $1.51 \mathrm{ng} / \mathrm{ml}$ was used, the sensitivity and specificity of serum AKR1B10 for diagnosing HCC were 81.0 and $60.9 \%$, respectively. Accordingly, the sensitivity and specificity for HCC were 69.0 and $82.0 \%$, respectively, if a cutoff value of $11.71 \mathrm{ng} / \mathrm{ml}$ of serum AFP was used. It appeared that a high specificity for HCC diagnosis could only be achieved when a high level of serum AFP was used. In addition, among patients with HCC with ARK1B10 $>1.51 \mathrm{ng} / \mathrm{ml}$, only 26 patients exhibited concentrations of AFP $<11.71 \mathrm{ng} / \mathrm{ml}$, which is the relative diagnostic threshold of AFP with the highest sensitivity and specificity. This finding further revealed that there was a marked expression of ARK1B10 before AFP becomes more clinical relevant. Furthermore, diagnostic performance of AKR1B10 and AFP for HCC was further assessed and compared (Table III). With 95\% confidence interval, the area under curve (AUC) for AKR1B10 [AUC=0.759 (0.697-0.821)] and AFP [AUC $=0.796$ (0.732-0.860)] was similar. No statistically significant difference in the performance for HCC diagnosis was identified between AFP and AKR1B10 ( $\mathrm{Z}=0.805, \mathrm{P}=0.390)$.

Complementary diagnostic performance of AKRIB1O with $A F P$ for HCC. The current findings suggest that ARK1B10 is a potential serum biomarker for early detection of HCC. The current study further explored whether concurrent measurement 

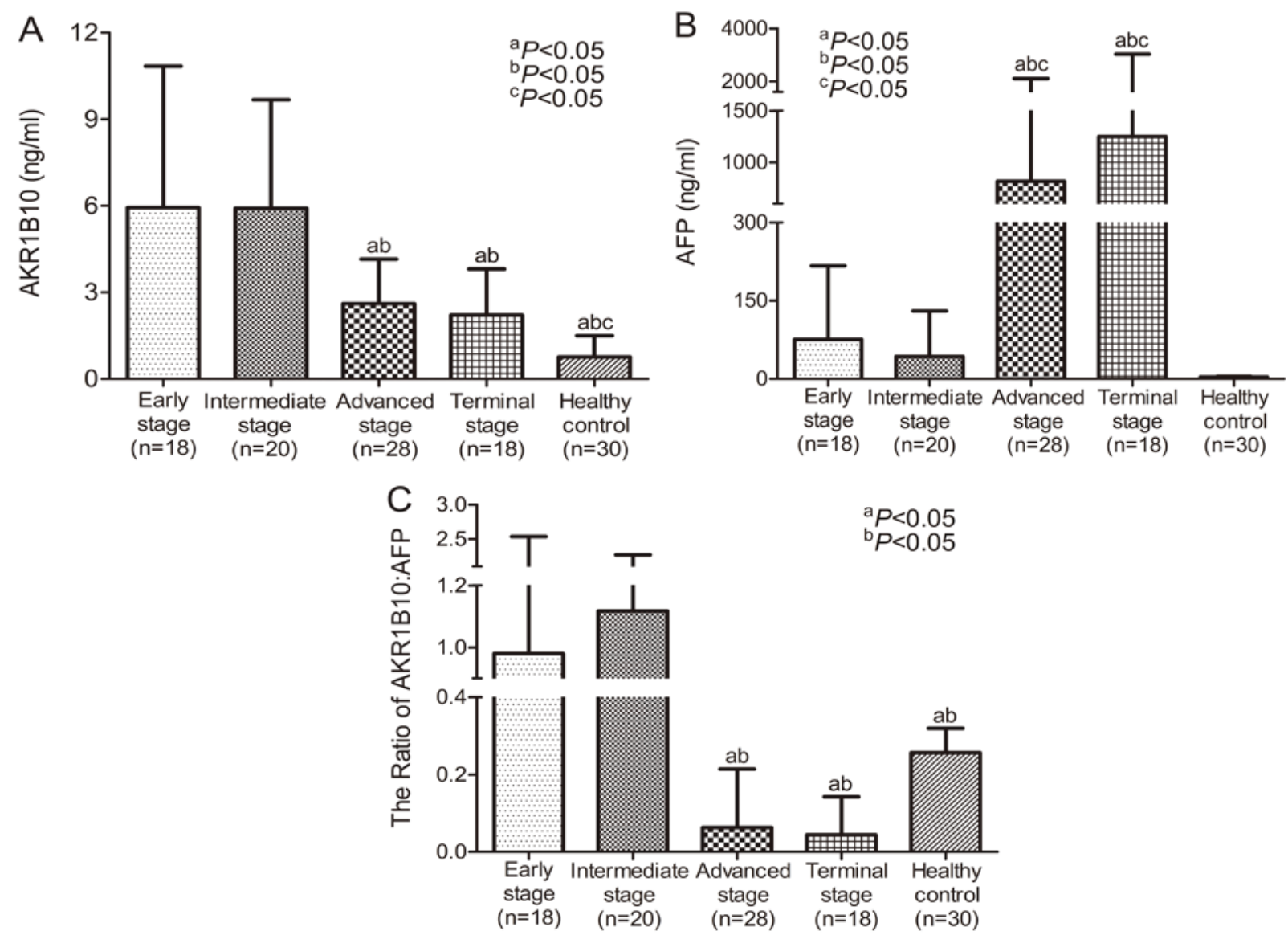

Figure 2. Mean expressions of serum AKR1B10 and AFP levels in patients with HCC at different pathological stages classified using Barcelona Clinic Liver Cancer staging. (A) A significant increase in AKR1B10 was observed in early- and intermediate-stage HCC. ${ }^{\mathrm{a} P}<0.05$ vs. patients with early stage. ${ }^{\text {b }} \mathrm{P}<0.05$ vs. patients with intermediate stage. ${ }^{~} \mathrm{P}<0.05$ vs. patients with advanced stage. (B) A significant increase in AFP was observed in advanced- and terminal-stage HCC. ${ }^{a} \mathrm{P}<0.05$ vs. patients with early stage. ${ }^{b} \mathrm{P}<0.05$ vs. patients with intermediate stage. ${ }^{\mathrm{C}} \mathrm{P}<0.05$ vs. healthy control. (C) The ratio of AKR1B10: AFP at different $\mathrm{HCC}$ stages. ${ }^{a} \mathrm{P}<0.05$ vs. patients with early stage. ${ }^{\mathrm{b}} \mathrm{P}<0.05$ vs. patients with intermediate stage. AKR1B10, aldo-keto reductase family 1 member $\mathrm{B} 10$; AFP, $\alpha$-fetoprotein; HCC, hepatocellular carcinoma.

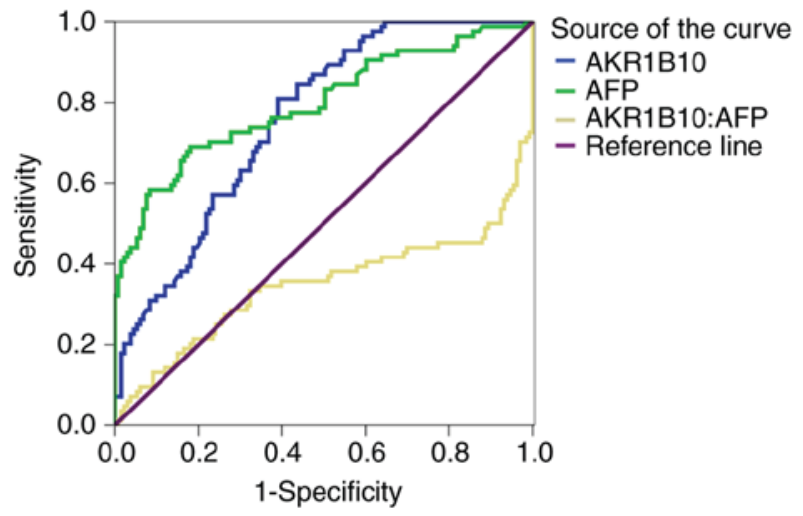

Figure 3. Receiver operating characteristic curve of the sensitivity and specificity of serum AKR1B10 and AFP for diagnosing HCC. AKR1B10, aldo-keto reductase family 1 member B10; AFP, $\alpha$-fetoprotein; HCC, hepatocellular carcinoma.

of ARK1B10 with AFP could increase the sensitivity of HCC diagnosis. As expected, a sensitivity of $92.86 \%$ (78/84) for HCC diagnosis was achieved when a combination of AKR1B10 and AFP proteins were measured. In addition, the specificity and positive predictive value for diagnosing HCC were 52.63\%
(70/133) and 55.32\% (78/141), respectively, with a negative predictive value as high as $92.11 \%$ (70/76) (Table IV). Compared with a single biomarker, the combined measurement of AKR1B10 and AFP levels markedly increased the sensitivity and negative predictive value for HCC diagnosis. Taken together, these findings demonstrate there is promise for developing a novel diagnostic approach to detect early stage HCC.

\section{Discussion}

HCC is notorious for its subtle onset and rapid progression (1). The vast majority of patients with HCC are already in advanced stage complicated with multiple intra- and extra-hepatic metastases when a diagnosis is confirmed (1). A reliable method allowing diagnosis of asymptomatic HCC is of paramount importance to reduce mortality and improve prognosis of patients with HCC (41). The current study assessed the diagnostic performance of AKR1B10 in diagnosing Chinese patients with $\mathrm{HCC}$ who had previously contracted either HBV or HCV infection. The current results indicated that patients with HCC have a significantly higher level of serum AKR1B10 compared with patients with hepatic cirrhosis and chronic hepatitis. Compared with advanced and terminal stage HCC, a significant increase in the concentration of AKR1B10 was 
Table III. Comparison of the AUC for serum AKR1B10 and AFP for HCC diagnosis.

\begin{tabular}{lccccr}
\hline Item & AUC & SE & $95 \%$ CI & Z-value & P-value \\
\hline AKR1B10 & 0.759 & 0.032 & $0.697-0.821$ & & \\
AFP & 0.796 & 0.033 & $0.732-0.860$ & & 0.390 \\
AFP-AKR1B10 & 0.037 & 0.046 & & 0.805 & \\
\hline
\end{tabular}

AKR1B10, aldo-keto reductase family 1 member B10; AFP, $\alpha$-fetoprotein; HCC, hepatocellular carcinoma; AUC, area under receiver operating characteristic curve; SE, standard error; CI, confidence interval.

Table IV. Diagnostic performance of serum AKR1B10 in combination with AFP in patients with HCC.

\begin{tabular}{lccc}
\hline AKR1B10/AFP & HCC & Non-HCC & Total \\
\hline AKR1B10 $>1.5 \mathrm{ng} / \mathrm{ml}$ & 78 & 63 & 141 \\
\pm AFP $>11.71 \mathrm{ng} / \mathrm{ml}$ & & & \\
Negative for both & 6 & 70 & 76 \\
Total & 84 & 133 & 217 \\
\hline
\end{tabular}

AKR1B10, aldo-keto reductase family 1 member B10; AFP, $\alpha$-fetoprotein; HCC, hepatocellular carcinoma.

detected in patients with early stage HCC, while AFP levels were below the threshold for HCC diagnosis.

HCCs are not homogeneous and certain HCCs may have normal or only mildly elevated levels of AFP compared with healthy individuals. The highest sensitivity and specificity of AFP for diagnosis of HCC (60-80\% and 70-90\%, respectively) was achieved at a cut of value of $16 \mathrm{~nm} / \mathrm{ml}(42)$, but AFP was not expressed in approximately $30-40 \%$ of patients with HCC, which makes this diagnostic approach less reliable (12). In the current study, in $31 \%$ (26/84) of patients with HCC, enhanced AKR1B10 expression was highly associated with HCC, while the concentration of AFP was still below its threshold for HCC diagnosis. This suggests that the concentration of AKR1B10 associates well with the development of HCC and thus could be a potential biomarker for early HCC detection.

For the high-risk population, it is recommended that serum AFP level measurement and liver ultrasonography be performed every 6 months as a screening method (43). However, the role of such an approach is devalued by the relatively low sensitivity and specificity of AFP as a reliable biomarker for identifying early stage HCC. The current study identified that $62 \%$ of patients with HCC $(52 / 84)$ had serum AFP levels of $<200 \mathrm{ng} / \mathrm{ml}$, and $200 \mathrm{ng} / \mathrm{ml}$ is considered to be the diagnostic value of HCC in clinical practice. Furthermore, by setting the ROC curve with a cutoff value of $11.095 \mathrm{ng} / \mathrm{ml}$, the sensitivity and specificity of AFP for diagnosing HCC were 77.1 and $81.2 \%$, respectively, which is consistent with previously published results (19). Unfortunately, AFP levels below the diagnostic threshold of $20 \mathrm{ng} / \mathrm{ml}$ were only sporadically observed in patients with HCC.

It is known that AKR1B10 expression is upregulated in HCC tissues $(31,32,37)$. However, to the best of our knowledge, its biological significance in molecular and pathological processes in $\mathrm{HCC}$ is poorly understood. So far, data from only a handful of studies suggest that serum AKR1B10 could be a convenient and potential biomarker for diagnosing HCC. The current findings indicate that serum AKR1B10 levels in patients with HCC were significantly higher compared with patients with non-cancerous hepatic disease, including liver cirrhosis and chronic hepatitis and further analysis demonstrated a strong association between AKR1B10 and HCC, as also reported by a previous study (31). Notably, with an AKR1B10 cutoff value of $1.51 \mathrm{ng} / \mathrm{ml}$ determined by an ROC curve in the current study, the sensitivity and specificity of AKR1B10 reach a level where diagnosis of HBV/HCV-related HCC could be achieved.

When the association of AKR1B10 levels with BCLC staging was considered, the current study identified a significant increase in serum AKR1B10 in patients with early and intermediate stage HCC compared with patients with advanced and terminal stage HCC. This unique pattern of expression is the opposite of that identified for AFP levels, which were the highest in the terminal stage. These findings strongly suggest there is a close association between the expression of ARK1B10 and early development of HCC. Although the upregulation of AKR1B10 expression is also observed in patients with HBV or HCV infections as well as hepatic fibrosis (34), it appears that elevation of AKR1B10, which has significant clinical implications, occurs as soon as hepatocytes begin to undergo cirrhosis, with the final pathohistological changes leading to liver cancer. As identified in the current study, both HBV and HCV increase serum AKR1B10, which was more pronounced in $\mathrm{HCC}$ and liver cirrhosis. Therefore, a robust expression of ARK1B10 during the early stage of HCC increases its candidacy as a potential biomarker compared with AFP, in the early detection of HCC. Furthermore, the current data support the notion that, with a concurrent evaluation of multiple potential biomarkers, which is still a focus of ongoing research, the rate of detection of early stage HCC could be improved, as reported previously (44). By combining AKR1B10 with AFP, there could be a notable improvement in the diagnostic performance and screening of HCC.

A limitation of the current study is the relatively small number of subjects. In addition, whether the association between serum AKR1B10 levels and tissue AKR1B10 expression in patients with HCC was linearly dependent or not was not investigated. In this regard, a prospective large sample analysis of the association between serum AKR1B10 levels 
and HCC tissues expression should be performed in multicenter studies. Furthermore, AKR1B10 expression was not exclusively revealed in malignant tumors; a low to moderate expression was also observed in the normal human tissues or non-neoplastic conditions. Therefore, further studies are required to characterize the specific role of AKR1B10 in liver cancer screening.

In conclusion, levels of AKR1B10 are significantly elevated in patients with HCC in a stage-dependent manner and could serve as a prospective serum biomarker for diagnosing $\mathrm{HBV} / \mathrm{HCV}$-related early HCC. The unique expression of AKR1B10 in early stage HCC makes it a stronger candidate biomarker compared with others for early detection of HCC. Furthermore, evaluating combined AKR1B10 and AFP levels has some promising clinical implications, since a high diagnostic accuracy for HCC by concurrently examining these two biomarkers appears to be achievable.

\section{Acknowledgements}

Not applicable.

\section{Funding}

The present study was funded by the National Science and Technology Major Project (grant nos. 2017ZX10201201, 2017ZX10202202 and 2017ZX10202203), the China National Science and Technology Key Project for Infectious Diseases Control for the consecutive 12th Five-Year Plan Period (grant no. 2012ZX10002003-003-010), the Liaoning Provincial Science and Technology Key Project for Translational Medicine (grant no. 2016509), the Liaoning Provincial Science and Technology Key Project for Translational Medicine (grant no. 2014225020), the Science and Technology Project of Liaoning Province (grant no. 2013225021) and the Outstanding Scientific Fund of Shengjing Hospital (grant no. 201102).

\section{Availability of data and materials}

All data generated or analyzed during the present study were included in this published study.

\section{Authors' contributions}

$\mathrm{CH}$ and LG gathered samples, analyzed and interpreted the patient data, and wrote the manuscript. $\mathrm{HB}$ and XD made contributions to conception, design and acquisition of funding. All authors read and approved the final manuscript.

\section{Ethics approval and consent to participate}

The study protocols were approved by the Ethics Committee of Shengjing Hospital of China Medical University (approval no. 2016PS105J) and written informed consent was obtained from all participants.

\section{Patient consent for publication}

Written informed consent for publication was obtained from all participants.

\section{Competing interests}

The authors declare that they have no competing interests.

\section{References}

1. Ministry of Health of the People's Republic of China: Diagnosis, management, and treatment of hepatocellular carcinoma (V2011). J Clini Hepatol 11: 1141-1159, 2011 (In Chinese).

2. Global Burden of Disease Cancer C, Fitzmaurice C, Dicker D, Pain A, Hamavid H, Moradi-Lakeh M, MacIntyre MF, Allen C, Hansen G, Woodbrook R, et al: The global burden of cancer 2013. JAMA Oncol 1: 505-527, 2015.

3. El-Serag HB: Hepatocellular carcinoma. N Engl J Med 365: 1118-1127, 2011.

4. McGlynn KA, Petrick JL and London WT: Global epidemiology of hepatocellular carcinoma: An emphasis on demographic and regional variability. Clin Liver Dis 19: 223-238, 2015.

5. Yang X, Gao JY, Wang J and Cheng J: The impact of anti-HBV treatment on the occurrence and recurrence of hepatocellular carcinoma: Focus on Asian studies. Discov Med 19: 89-99, 2015.

6. Forner A, Llovet JM and Bruix J: Hepatocellular carcinoma. Lancet 379: 1245-1255, 2012.

7. Bruix J, Sherman M and Practice Guidelines Committee, American Association for the Study of Liver Diseases: Management of hepatocellular carcinoma. Hepatology 42: 1208-1236, 2005

8. Tsuchiya N, Sawada Y, Endo I, Saito K, Uemura Y and Nakatsura T: Biomarkers for the early diagnosis of hepatocellular carcinoma. World J Gastroenterol 21: 10573-10583, 2015.

9. Spangenberg HC, Thimme R and Blum HE: Serum markers of hepatocellular carcinoma. Semin Liver Dis 26: 385-390, 2006.

10. Aghoram R, Cai P and Dickinson JA: Alpha-foetoprotein and/or liver ultrasonography for screening of hepatocellular carcinoma in patients with chronic hepatitis B. Cochrane Database Syst Rev CD002799, 2012.

11. Chun S, Rhie SY, Ki CS, Kim JE and Park HD: Evaluation of alpha-fetoprotein as a screening marker for hepatocellular carcinoma in hepatitis prevalent areas. Ann Hepatol 14: 882-888, 2015.

12. Giannini EG, Marenco S, Borgonovo G, Savarino V, Farinati F, Del Poggio P, Rapaccini GL, Anna Di Nolfo M, Benvegnù L, Zoli M, et al: Alpha-fetoprotein has no prognostic role in small hepatocellular carcinoma identified during surveillance in compensated cirrhosis. Hepatology 56: 1371-1379, 2012.

13. Dai M, Chen X, Liu X, Peng Z, Meng J and Dai S: Diagnostic value of the combination of Golgi Protein 73 and alpha-fetoprotein in hepatocellular carcinoma: A meta-analysis. PLoS One 10: e0140067, 2015.

14. Li D, Mallory T and Satomura S: AFP-L3: A new generation of tumor marker for hepatocellular carcinoma. Clin Chim Acta 313: 15-19, 2001.

15. Sato Y, Nakata K, Kato Y, Shima M, Ishii N, Koji T, Taketa K, Endo Y and Nagataki S: Early recognition of hepatocellular carcinoma based on altered profiles of alpha-fetoprotein. N Engl J Med 328: 1802-1806, 1993.

16. Marrero JA, Feng Z, Wang Y, Nguyen MH, Befeler AS, Roberts LR, Reddy KR, Harnois D, Llovet JM, Normolle D, et al: Alpha-fetoprotein, des-gamma carboxyprothrombin, and lectin-bound alpha-fetoprotein in early hepatocellular carcinoma. Gastroenterology 137: 110-118, 2009.

17. Sterling RK, Jeffers L, Gordon F, Venook AP, Reddy KR, Satomura S, Kanke F, Schwartz ME and Sherman M: Utility of Lens culinaris agglutinin-reactive fraction of alpha-fetoprotein and des-gamma-carboxy prothrombin, alone or in combination, as biomarkers for hepatocellular carcinoma. Clin Gastroenterol Hepatol 7: 104-113, 2009.

18. Lok AS, Sterling RK, Everhart JE, Wright EC, Hoefs JC, Di Bisceglie AM, Morgan TR, Kim HY, Lee WM, Bonkovsky HL and Dienstag JL; HALT-C Trial Group: Des-gamma-carboxy prothrombin and alpha-fetoprotein as biomarkers for the early detection of hepatocellular carcinoma. Gastroenterology 138: 493-502, 2010.

19. Ertle JM, Heider D, Wichert M, Keller B, Kueper R, Hilgard P, Gerken $G$ and Schlaak JF: A combination of $\alpha$-fetoprotein and des-U-carboxy prothrombin is superior in detection of hepatocellular carcinoma. Digestion 87: 121-131, 2013. 
20. Pote N, Cauchy F, Albuquerque M, Voitot H, Belghiti J, Castera L, Puy H, Bedossa P and Paradis V: Performance of PIVKA-II for early hepatocellular carcinoma diagnosis and prediction of microvascular invasion. J Hepatol 62: 848-854, 2015.

21. Ma J, Yan R, Zu X, Cheng JM, Rao K, Liao DF and Cao D: Aldo-keto reductase family $1 \mathrm{~B} 10$ affects fatty acid synthesis by regulating the stability of acetyl-CoA carboxylase-alpha in breast cancer cells. J Biol Chem 283: 3418-3423, 2008.

22. Wang C, Yan R, Luo D, Watabe K, Liao DF and Cao D: Aldo-keto reductase family 1 member B10 promotes cell survival by regulating lipid synthesis and eliminating carbonyls. J Biol Chem 284: 26742-26748, 2009.

23. Cao D, Fan ST and Chung SS: Identification and characterization of a novel human aldose reductase-like gene. J Biol Chem 273: 11429-11435, 1998.

24. Conklin D, Prough R and Bhatanagar A: Aldehyde metabolism in the cardiovascular system. Mol Biosyst 3: 136-150, 2007.

25. Spite M, Baba SP, Ahmed Y, Barski OA, Nijhawan K, Petrash JM, Bhatnagar A and Srivastava S: Substrate specificity and catalytic efficiency of aldo-keto reductases with phospholipid aldehydes. Biochem J 405: 95-105, 2007.

26. Yan R, Zu X, Ma J, Liu Z, Adeyanju M and Cao D: Aldo-keto reductase family $1 \mathrm{~B} 10$ gene silencing results in growth inhibition of colorectal cancer cells: Implication for cancer intervention. Int J Cancer 121: 2301-2306, 2007.

27. Martin HJ and Maser E: Role of human aldo-keto-reductase AKR1B10 in the protection against toxic aldehydes. Chem Biol Interact 178: 145-150, 2009.

28. Zhong L, Liu Z, Yan R, Johnson S, Zhao Y, Fang X and Cao D Aldo-keto reductase family 1 B10 protein detoxifies dietary and lipid-derived alpha, beta-unsaturated carbonyls at physiological levels. Biochem Biophys Res Commun 387: 245-250, 2009.

29. Crosas B, Hyndman DJ, Gallego O, Martras S, Parés X, Flynn TG and Farrés J: Human aldose reductase and human small intestine aldose reductase are efficient retinal reductases: Consequences for retinoid metabolism. Biochem J 373: 973-979, 2003.

30. Gallego O, Belyaeva OV, Porte S, Ruiz FX, Stetsenko AV, Shabrova EV, Kostereva NV, Farrés J, Parés X and Kedishvili NY: Comparative functional analysis of human medium-chain dehydrogenases, short-chain dehydrogenases/reductases and aldo-keto reductases with retinoids. Biochem J 399: 101-109, 2006.

31. Matkowskyj KA, Bai H, Liao J, Zhang W, Li H, Rao S, Omary R and Yang GY: Aldoketoreductase family 1B10 (AKR1B10) as a biomarker to distinguish hepatocellular carcinoma from benign liver lesions. Hum Pathol 45: 834-843, 2014.

32. Heringlake S, Hofdmann M, Fiebeler A, Manns MP, Schmiegel W and Tannapfel A: Identification and expression analysis of the aldo-ketoreductase1-B10 gene in primary malignant liver tumours. J Hepatol 52: 220-227, 2010

33. Luo DX, Huang MC, Ma J, Gao Z, Liao DF and Cao D: Aldo-keto reductase family 1 , member $\mathrm{B} 10$ is secreted through a lysosome-mediated non-classical pathway. Biochem J 438: 71-80, 2011.
34. Sato S, Genda T, Hirano K, Tsuzura H, Narita Y, Kanemitsu Y, Kikuchi T, Iijima K, Wada R and Ichida T: Up-regulated aldo-keto reductase family 1 member B10 in chronic hepatitis C: Association with serum alpha-fetoprotein and hepatocellular carcinoma. Liver Int 32: 1382-1390, 2012.

35. Mori M, Genda T, Ichida T, Murata A, Kamei M, Tsuzura H, Sato S, Narita Y, Kanemitsu Y, Ishikawa S, et al: Aldo-keto reductase family 1 member B10 is associated with hepatitis B virus-related hepatocellular carcinoma risk. Hepatol Res 47: E85-E93, 2017.

36. Murata A, Genda T, Ichida T, Amano N, Sato S, Tsuzura H, Sato S, Narita Y, Kanemitsu Y, Shimada Y, et al: Pretreatment AKR1B10 expression predicts the risk of hepatocellular carcinoma development after hepatitis $\mathrm{C}$ virus eradication. World $\mathrm{J}$ Gastroenterol 22: 7569-7578, 2016.

37. Schmitz KJ, Sotiropoulos GC, Baba HA, Schmid KW, Müller D, Paul A, Auer T, Gamerith G and Loeffler-Ragg J: AKR1B10 expression is associated with less aggressive hepatocellular carcinoma: A clinicopathological study of 168 cases. Liver Int 31: 810-816, 2011.

38. Ha SY, Song DH, Lee JJ, Lee HW, Cho SY and Park CK: High expression of aldo-keto reductase 1B10 is an independent predictor of favorable prognosis in patients with hepatocellular carcinoma. Gut Liver 8: 648-654, 2014.

39. Chinese Society of Hepatology and Chinese Society of Infectious Diseases, Chinese Medical Association: The guideline of prevention and treatment for chronic hepatitis B (2010 version). Zhonghua Gan Zang Bing Za Zhi 19: 13-24, 2011 (In Chinese).

40. Llovet JM, Brú $\mathrm{C}$ and Bruix J: Prognosis of hepatocellular carcinoma: The BCLC staging classification. Semin Liver Dis 19: 329-338, 1999.

41. Bruix J, Sherman M and American Association for the Study of Liver Diseases: Management of hepatocellular carcinoma: An update. Hepatology 53: 1020-1022, 2011.

42. Trevisani F, D'Intino PE, Morselli-Labate AM, Mazzella G, Accogli E, Caraceni P, Domenicali M, De Notariis S, Roda E and Bernardi M: Serum alpha-fetoprotein for diagnosis of hepatocellular carcinoma in patients with chronic liver disease: Influence of HBsAg and anti-HCV status. J Hepatol 34: 570-575, 2001.

43. Bellissimo F, Pinzone MR, Cacopardo B and Nunnari G: Diagnostic and therapeutic management of hepatocellular carcinoma. World J Gastroenterol 21: 12003-12021,2015.

44. Chaiteerakij R, Zhang X, Addissie BD, Mohamed EA, Harmsen WS, Theobald PJ, Peters BE, Balsanek JG, Ward MM, Giama NH, et al: Combinations of biomarkers and Milan criteria for predicting hepatocellular carcinoma recurrence after liver transplantation. Liver Transpl 21: 599-606, 2015.

This work is licensed under a Creative Commons Attribution-NonCommercial-NoDerivatives 4.0 International (CC BY-NC-ND 4.0) License. 